\begin{tabular}{|c|c|c|c|c|c|c|c|c|c|c|}
\hline & Age $>75$ & $\begin{array}{c}\text { Sex } M \text { vs } \\
F\end{array}$ & Residence & $\begin{array}{l}\text { Hepatic } \\
\text { Disease }\end{array}$ & CRF & OCFA & Dementia & CHF & $\begin{array}{l}\text { Diabetes } \\
\text { mellitus }\end{array}$ & $\begin{array}{c}\text { Charlson } \mathrm{i} . \\
>2\end{array}$ \\
\hline $\begin{array}{l}\mathrm{HR} \\
\text { IC } \\
95 \%\end{array}$ & $\begin{array}{c}1,05 \\
(1.04- \\
1.06)\end{array}$ & $\begin{array}{c}1,32 \\
(1.21-1.44)\end{array}$ & $\begin{array}{c}1,48 \\
(1.36-1.60)\end{array}$ & $\begin{array}{c}3,25 \\
(2.17-4.86)\end{array}$ & $\begin{array}{c}1,87 \\
(1.60- \\
2.18)\end{array}$ & $\begin{array}{c}1,46 \\
(1.30- \\
1.64)\end{array}$ & $\begin{array}{c}1,46 \\
(1.30-1.62)\end{array}$ & $\begin{array}{c}2,50 \\
(2.07- \\
3.00)\end{array}$ & $\begin{array}{c}1,11 \\
(1.02-1.22)\end{array}$ & $\begin{array}{c}1,98 \\
(1.73-2.26)\end{array}$ \\
\hline
\end{tabular}

Conclusions: Among women with high risk of future fracture, having been told by a health care provider that they had osteoporosis/osteopenia was independently associated with considering taking medications for osteoporosis. Our results suggest that in considering osteoporosis intervention design efficiency and effectiveness, women's recognition of a diagnosis of osteoporosis/osteopenia are critical components to be considered when attempting to influence stage of behaviour transitions.

Disclosure of Interest: M. I. Danila: None declared, E. Rahn: None declared, A. Mudano: None declared, R. Outman: None declared, P. Li: None declared, D. Redden: None declared, F. Anderson Grant/research support from: Portola, Consultant for: Millennium Pharmaceuticals, S. Greenspan Grant/research support from: Amgen, Lilly, Consultant for: Merck, A. LaCroix Consultant for: Amgen, Pfizer, Sermonix, J. Nieves: None declared, S. Silverman Grant/research support from: Amgen, Lilly, Consultant for: Amgen, Speakers bureau: Amgen, Lilly, E. Siris Consultant for: Amgen, Radius, N. Watts Shareholder of: OsteoDynamics, Grant/ research support from: Shire, Consultant for: AbbVie, Amgen, Janssen, Merck, Radius, Sanofi, Paid instructor for: Amgen, Shire, S. Ladores: None declared, K. Meneses: None declared, J. Curtis Grant/research support from: Amgen, Consultant for: Amgen, K. Saag Grant/research support from: Amgen, Lilly, Merck, Consultant for: Amgen, Lilly, Merck

DOI: 10.1136/annrheumdis-2018-eular.4802

\section{THU0473 TREND OF MORTALITY AFTER OSTEOPOROTIC HIP FRACTURE IN A PERIOD OF 17 YEARS}

R. Mazzucchelli' ${ }^{1}$ O. Guzón-lllescas ${ }^{2}$, E. Pérez-Fernandez ${ }^{2}$, M. Peña ${ }^{2}$, J. Quirós ${ }^{2}$, N. Crespí_Villarías ${ }^{3}$, A. García-Vadillo ${ }^{4}{ }^{1}$ Rheumatology; ${ }^{2}$ Hospital U. Función Alcorcón; ${ }^{3}$ C.S La Rivota, Alcorcón; ${ }^{4}$ H. U. La Princesa, Madrid, Spain

Background: It is known that the mortality after a hip fracture is increased with respect to the general population. However, the trend of mortality is a controversial issue.

Objectives: The objective of this study is to analyse the incidence, trend and factors associated with mortality in patients with osteoporotic hip fracture.

Methods: This is a retrospective cohort study using the Minimum Basic Data Set (MBDS) of our hospital that collects a minimum data set at hospital discharge. We identified patients older than 45 years who suffered an osteoporotic hip fracture during the period from 1999 to 2015. (3992 hip fractures). The demographic data and comorbidities were obtained from the exploitation of the MBDS and the Income Nursing Assessment Form (subgroup of 810 patients). The identification of the deceased was obtained by consulting the MBDS and the INDEF (National Death Index facilitated by the Ministry of Health). A survival analysis was performed (regression of Cox and Kaplan-Meier). The incidence rate, standardised mortality index (SMI) was calculated with respect to the mortality of the general population of Madrid (mortality data of the general population obtained INE), trend (Poisson regression) and risk (Hazard Ratio) for the different clinical and demographic variables.

Results: The cumulative incidence of mortality was $72.69 \%$ in the study period. The crude mortality rate at $1,3,6$ months and 1 and 3 years was $9.2 \%, 17.4 \%$, $24.6 \%, 33 \%$ and $56 \%$, respectively. In men it was $13.7 \%, 25 \%, 32.7 \%, 43.3 \%$ and $65.6 \%$ and in women $7.9 \%, 15.7 \%, 22.3 \%, 30 \%, 53.2 \%$. The median overall survival was 886 days (95\% Cl: 836-951), with 576 for men and 998 for women. A statistically significant reduction in median survival was observed throughout the study period. The IME was 8.3 (95\% Cl: 7.98-8.59); (similar values in men and women). The clinical-demographic variables that showed a statistically significant association with mortality are shown in the following table 1 (HR and p-value): Other variables that showed statistical association were: presence of auditory and visual alterations, incontinence (urinary and faecal) and the total score on the Norton scale and the Downton scale.

Conclusions: We found an increase in mortality (or decrease in median survival) of patients with hip fracture during the last 17 years. An oncrease in mortality has been observed in patients with hip fracture related to age, male sex, diabetes, hepatic disease and living in a nursing home.

Disclosure of Interest: None declared

DOI: 10.1136/annrheumdis-2018-eular.1512

\section{THU0474}

\section{UTILISATION OF ANTI-OSTEOPOROTIC DRUGS IN REAL-WORLD DATA: AN ANALYSIS OF PERSISTENCE TO THERAPY AND RISK OF FRACTURE}

V. Orlando ${ }^{1}$, V.M. Monettii ${ }^{1}$, F. Guerriero ${ }^{1}$, A. Moretti ${ }^{2}$, V. Russo ${ }^{1}$, A. Piscitelli ${ }^{1}$ G. Iolascon' ${ }^{2}$, E. Menditto ${ }^{1} .{ }^{1}$ CIRFF Center of Pharmacoeconomics, University of Naples Federico II; ${ }^{2}$ Department of Medical and Surgical Specialties and Dentistry, University of Campania "Luigi Vanvitelli", Naples, Italy

Background: Osteoporosis is a chronic progressive disease characterised by low bone mass and deterioration of bone structure, leading to an increate risk of fractures. It is a major public health problem, affecting hundreds of millions of people worldwide. The primary aim of pharmaceutical therapy is to reduce the risk of osteoporotic fractures. However, long-term adherence to therapy is requie for optimal therapeutic benefit for patients with osteoporosis. Poor adherence is considered to be one primary reason for suboptimal clinical benefit.

Objectives: The aim of this study was to investigate the determinants of non-persistence and impact of persistence on the risk of fractures by using administrative databases.

Methods: We conducted a retrospective cohort study using administrative data from four local health authorities in the Abruzzo Region (Central Italy), which comprise about 900000 inhabitants (68\% of the overall regional population). The final cohort consisted of a total of 7862 patients, aged $\geq 60$ years, identified through records of filled prescriptions for an antiosteoporotic drug between January 1, 2006 to December 31,2006 . The primary outcome of this study was persistence at one year. Persistence was defined as the length of time (in days) from the date of the index prescription to the date of discontinuation therapy.

Results: Kaplan - Meier analysis showed that 3733 patients (47.5\%) were persistent with antiosteoporotic drugs after 1 year. An adjusted analysis showed that there is a big difference in persistence between women and men: women are more likely to be non-persistent than men (HR:1.94). Switcher patients were more likely to be non-persistent (HR:1.22). The odds of fracture were significantly higher for patients with previous fractures in comparison with those without previous fractures [OR, 1.70, $(95 \% \mathrm{Cl}, 1.12-2.59)]$ (table 1)

Table 1 Logistic regression model: impact of persistence and other factors on the risk fracture

\begin{tabular}{|c|c|c|c|c|}
\hline Characteristics & Unadjusted $\mathrm{OR}(95 \% \mathrm{CI})$ & $p$-value & Adjusted OR $(95 \% \mathrm{CI})$ & $p$-value \\
\hline \multicolumn{5}{|l|}{ Gender } \\
\hline Male & Reference & & & \\
\hline Female & $1.31(0.93-1.85)$ & 0.119 & $1.28(0.91-1.82)$ & 0.159 \\
\hline \multicolumn{5}{|l|}{ Age } \\
\hline $60-69$ & Reference & & & \\
\hline $70-79$ & $1.54(1.14-2.06)$ & 0.005 & $1.52(1.13-2.06)$ & 0.006 \\
\hline$\geq 80$ & $2.56(1.89-3.45)$ & $<0.001$ & $2.49(1.83-3.39)$ & $<0.001$ \\
\hline \multicolumn{5}{|l|}{ Previous fractures } \\
\hline No & Reference & & & \\
\hline Yes & $1.71(1.58-1.84)$ & $<0.01$ & $1.70(1.12-2.59)$ & 0.013 \\
\hline \multicolumn{5}{|l|}{ Persistence } \\
\hline No & Reference & & & \\
\hline Yes & $0.78(0.63-0.97)$ & 0.022 & $0.79(0.63-0.97)$ & 0.026 \\
\hline \multicolumn{5}{|l|}{ ACCI } \\
\hline Zero score $[0]$ & Reference & & & \\
\hline Mild score [1-4] & $0.86(0.32-2.36)$ & 0.772 & $1.35(0.49-3.78)$ & 0.562 \\
\hline Severe score $[\geq 5]$ & $1.50(1.06-2.12)$ & 0.022 & $1.33(0.94-1.90)$ & 0.112 \\
\hline
\end{tabular}

Conclusions: Persistence with antiosteoporotic drugs is a significant predictor of incurring a fracture. For these reason, improving osteoporosis treatment compliance and persistence represents one of a major challenge for the future.

\section{REFERENCES:}

[1] Casula M, Filippi A, Flacco E, Gambera M, Manzoli L, Menditto E, Orlando V, Piccinelli R, Tragni E, Catapano A. Assessment and potential determinats of compliance and persistence to anti-osteoporosis therapy in Italy. Am J Manag Care 2014;20(5):e138-e145.

[2] Iolascon G, Gimigliano F, Orlando V, Capaldo A, Di Somma C, Menditto E. Osteoporosis drugs in real-world clinical practice: an analysis of persistence. Aging Clin Exp Res 2013 Oct;25 Suppl 1:S137-41. 